\title{
Electronic cigarette nicotine delivery can exceed that of combustible cigarettes: a preliminary report
}

\author{
Carolina P Ramôa, ${ }^{1,2}$ Marzena M Hiler, ${ }^{1,2}$ Tory R Spindle, ${ }^{1,2}$ Alexa A Lopez, ${ }^{1,2}$ \\ Nareg Karaoghlanian, ${ }^{4}$ Thokozeni Lipato, ${ }^{1,3}$ Alison B Breland, ${ }^{1,2}$ Alan Shihadeh, ${ }^{1,4}$ \\ Thomas Eissenberg ${ }^{1,2}$
}

${ }^{1}$ Center for the Study of Tobacco Products, Virginia Commonwealth University, Richmond, Virginia, USA ${ }^{2}$ Department of Psychology, Virginia Commonwealth University, Richmond, Virginia, USA

${ }^{3}$ Department of Internal Medicine, Virginia Commonwealth University, Richmond, Virginia, USA ${ }^{4}$ Department of Mechanical Engineering, American University of Beirut, Beirut, Lebanon

\section{Correspondence to Dr Thomas Eissenberg, Department of Psychology, Center for the Study of Tobacco Products, College of Humanities and Sciences, Virginia Commonwealth University, 1112 East Clay Street, Suite B-08, PO Box 980205, Richmond, \\ VA 23298, USA; teissenb@vcu.edu}

Received 5 May 2015 Accepted 13 August 2015 Published Online First 31 August 2015

\section{ABSTRACT \\ Introduction Electronic cigarettes (ECIGs) aerosolise a liquid that usually contains propylene glycol and/or vegetable glycerine, flavourants and the dependence- producing drug, nicotine, in various concentrations. This laboratory study examined the relationship between liquid nicotine concentration and plasma nicotine concentration and puffing behaviour in experienced ECIG users.}

Methods Sixteen ECIG-experienced participants used a 3.3-Volt ECIG battery attached to a 1.5-0hm dual-coil 'cartomiser' loaded with $1 \mathrm{~mL}$ of a flavoured propylene glycol/vegetable glycerine liquid to complete four sessions, at least 2 days apart, that differed by nicotine concentration $(0,8,18$ or $36 \mathrm{mg} / \mathrm{mL})$. In each session, participants completed two 10-puff ECIG-use bouts (30 s puff interval) separated by 60 min. Venous blood was sampled to determine plasma nicotine concentration. Puff duration, volume and average flow rate were measured.

Results Immediately after bout 1, mean plasma nicotine concentration was $5.5 \mathrm{ng} / \mathrm{mL}(S D=7.7)$ for $0 \mathrm{mg} / \mathrm{mL}$ liquid, with significantly $(p<0.05)$ higher mean concentrations observed for the 8 (mean $=17.8 \mathrm{ng} / \mathrm{mL}$, $\mathrm{SD}=14.6), 18$ (mean=25.9 ng/mL, SD=17.5) and $36 \mathrm{mg} / \mathrm{mL}$ (mean=30.2 ng/mL; SD=20.0) concentrations; a similar pattern was observed for bout 2 . For bout 1 , at $36 \mathrm{mg} / \mathrm{mL}$, the mean post- minus pre-bout difference was $24.1 \mathrm{ng} / \mathrm{mL}$ ( $S D=18.3$ ). Puff topography data were consistent with previous results and revealed few reliable differences across conditions.

Discussion This study demonstrates a relationship between ECIG liquid nicotine concentration and user plasma nicotine concentration in experienced ECIG users. Nicotine delivery from some ECIGs may exceed that of a combustible cigarette. The rationale for this higher level of nicotine delivery is uncertain.

\section{INTRODUCTION}

Electronic cigarettes (ECIGs) are an evolving product class with an electric heating element that aerosolises a liquid often containing propylene glycol, vegetable glycerine, flavourants and the dependence-producing drug, nicotine. ECIG use is

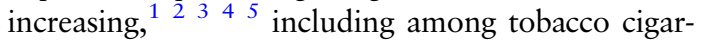
ette smokers using them as smoking cessation aids. ${ }^{2}{ }^{6}$ Effective ECIG-mediated smoking cessation may depend on a given product's ability to deliver nicotine, which can vary. ${ }^{79}$ Interestingly, experienced users puff differently than ECIG-naïve combustible cigarette smokers, ${ }^{10} 1112$ and this modified puffing behaviour likely influences product nicotine yield. ${ }^{13}$ Other factors also can influence nicotine yield, including device features and liquid nicotine concentration. To date, there has been little systematic exploration of how these factors might influence nicotine delivery in experienced ECIG users. One purpose of this study was to examine the extent to which liquid nicotine concentration influences the plasma nicotine concentration of experienced ECIG users. A secondary purpose was to examine how puff topography was influenced by liquid nicotine concentration.

\section{METHODS}

Participants

Sixteen experienced ECIG users completed this Institutional Review Board-approved study. Eligibility criteria included age between 18 and 55 years, and using $\geq 1 \mathrm{~mL}$ ECIG liquid/day for $\geq 3$ months at a liquid nicotine concentration of $\geq 12 \mathrm{mg} / \mathrm{mL}$. Exclusion criteria included history of chronic disease or psychiatric condition, regular use of a prescription medication (except vitamins and/or birth control), marijuana use $>10$ days and/or alcohol use $>25$ days in the past 30 days, use of other illicit drugs in the past 30 days and pregnancy.

\section{Procedure}

Similar to another report (A Lopez, M Hiler, E Soule, et al, In Press. Effects of Electronic Cigarette Liquid Nicotine Concentration on Plasma Nicotine and Puff Topography in Tobacco Cigarette Smokers: A Preliminary Report. Nicotine and Tobacco Research), all participants completed four independent, double-blind sessions preceded by instructions to abstain from tobacco/nicotine for $>12 \mathrm{~h}$, separated by $>48 \mathrm{~h}$, and randomised. In each session, participants were provided with an 'eGo' 3.3-Volt, $1000 \mathrm{mAh}$ battery with a 1.5 -Ohm, dual-coil, 510-style cartomiser preloaded (by staff with no participant contact) with $1 \mathrm{~mL}$ of a flavoured (tobacco or menthol), 70\% propylene glycol/30\% vegetable glycerine liquid. Sessions differed by liquid nicotine concentration: $0,8,18$ or $36 \mathrm{mg} / \mathrm{mL}$. Liquid nicotine concentration was verified throughout, and, on average, actual nicotine content was $\pm 1 \mathrm{mg}$ of labelled nicotine content. In each session, participants completed two, 10-puff ECIG-use bouts (separated by $60 \mathrm{~min}$ as in previous work), ${ }^{14}$ with a $30 \mathrm{~s}$ inter-puff interval. Venous blood was sampled 10 times in each session (10 min prior to and 5, 15, 30, 45 and $55 \mathrm{~min}$ after bout 1, and 5, 15, 30 and $45 \mathrm{~min}$ after bout 2) to assess plasma nicotine concentration. ${ }^{15}$ Puff 
duration, volume and peak flow were measured. ${ }^{10}$ Other outcomes (eg, subjective effects) were assessed but are not the focus of this preliminary report and are not discussed further.

\section{Statistical analyses}

For plasma nicotine data, in order to maintain statistical power while limiting type I error, we conducted a set of a priori comparisons using dependent sample $t$ tests in which, at each measurement timepoint, the mean plasma nicotine concentration for the $0 \mathrm{mg} / \mathrm{mL}$ condition was compared to the mean of the 8,18 and $36 \mathrm{mg} / \mathrm{mL}$ condition. Because these comparisons were nonorthogonal, a Bonferroni correction was applied. ${ }^{16}$ For topography data, we used the same analytic strategy within each bout, but compared across bouts within each concentration using uncorrected dependent sample $t$ tests for these orthogonal comparisons.

\section{RESULTS}

\section{Participant characteristics}

Of the 15 men and 1 woman who participated, 11 selfidentified as Caucasian, 3 African-American, 1 Hawaiian/Pacific Islander and 1 as other. Mean (SD) age was 29.6 (5.8) years. On average, participants had been using ECIGs for $1.4(0.9)$ years and consumed $2.0(1.4) \mathrm{mL}$ nicotine liquid daily at 19.8 (5.9) $\mathrm{mg} / \mathrm{mL}$ nicotine concentration. Thirteen did not smoke and three smoked an average of 2.3 (0.9) cigarettes/day for 1.7 (2.3) years. At screening, average expired air carbon monoxide (CO) concentration was 3.5 (2.4) parts/million.

\section{Plasma nicotine}

Figure 1 depicts mean plasma nicotine concentration over time by liquid nicotine concentration. Significant $(p<0.05)$ differences were observed between 0 and $8 \mathrm{mg} / \mathrm{mL}$ immediately after the first bout (timepoint $5 \mathrm{~min}$ ) through $45 \mathrm{~min}$ and also immediately after the second bout (timepoint 65) through $105 \mathrm{~min}$ $(\operatorname{ts}(15)<-3.2)$, between 0 and $18 \mathrm{mg} / \mathrm{mL}$ immediately after the first bout through $45 \mathrm{~min}$ and immediately after the second bout through $105 \mathrm{~min}$ (ts $(15)<-3.2$ ), and between 0 and $36 \mathrm{mg} / \mathrm{mL}$ immediately after the first bout, and thereafter (ts(15) $<-3.0)$. Immediately following the first bout, mean (SD) plasma nicotine concentration for the $0 \mathrm{mg} / \mathrm{mL}$ liquid nicotine concentration was 5.4 (7.7) ng/mL, for $8 \mathrm{mg} / \mathrm{mL}$ it was 17.8 (14.6) $\mathrm{ng} / \mathrm{mL}$, for $18 \mathrm{mg} / \mathrm{mL}$ it was $25.9(17.5) \mathrm{ng} / \mathrm{mL}$ and for $36 \mathrm{mg} / \mathrm{mL}$ it was $30.2(20.0) \mathrm{ng} / \mathrm{mL}$. The difference from baseline following the first bout was $-4.4(17.9) \mathrm{ng} / \mathrm{mL}$ for $0 \mathrm{mg} / \mathrm{mL}, 11.1 \mathrm{ng} / \mathrm{mL}$ (9.4) for $8 \mathrm{mg} / \mathrm{mL}, 18.1 \mathrm{ng} / \mathrm{mL}$ (15.5) for $18 \mathrm{mg} / \mathrm{mL}$ and 24.1 (18.2) $\mathrm{ng} / \mathrm{mL}$ for $36 \mathrm{mg} / \mathrm{mL}$. Immediately following the second bout, mean plasma nicotine concentration for $0 \mathrm{mg} / \mathrm{mL}$ was 4.4 (4.6) $\mathrm{ng} / \mathrm{mL}$, for $8 \mathrm{mg} / \mathrm{mL}$ it was $16.9(11.2) \mathrm{ng} / \mathrm{mL}$, for $18 \mathrm{mg} / \mathrm{mL}$ it was $23.6(16.1) \mathrm{ng} / \mathrm{mL}$ and for $36 \mathrm{mg} / \mathrm{mL}$ it was 24.7 (17.0) $\mathrm{ng} / \mathrm{mL}$.

\section{Puff topography}

For bout 1, mean (SD) volume was $154.5 \mathrm{~mL}$ (155.5) for $0 \mathrm{mg} / \mathrm{mL}$, $176.0 \mathrm{~mL}$ (131.6) for $8 \mathrm{mg} / \mathrm{mL}, 114.7 \mathrm{~mL}$ (61.9) for $18 \mathrm{mg} / \mathrm{mL}$ and $78.5 \mathrm{~mL}(39.5) \mathrm{mL}$ for $36 \mathrm{mg} / \mathrm{mL}$. The difference between 0 and $36 \mathrm{mg} / \mathrm{mL}$ was not significant with the Bonferroni correction, though this difference would have been significant without it. Also, for bout 1, mean puff duration was $5.5 \mathrm{~s}$ (2.04) for $0 \mathrm{mg} / \mathrm{mL}, 5.5 \mathrm{~s}(2.11)$ for $8 \mathrm{mg} / \mathrm{mL}, 4.97 \mathrm{~s} \mathrm{(1.69)} \mathrm{for} 18 \mathrm{mg} / \mathrm{mL}$ and $3.98 \mathrm{~s}(1.54)$ for $36 \mathrm{mg} / \mathrm{mL}$. The difference between 0 and $36 \mathrm{mg} / \mathrm{mL}$ was significant $(\mathrm{t}(15)=4.7)$. Mean flow rate was $33.8 \mathrm{~mL} / \mathrm{s}$ (33.1) for $0 \mathrm{mg} / \mathrm{mL}, 30.8 \mathrm{~mL} / \mathrm{s}$ (20.7) for $8 \mathrm{mg} / \mathrm{mL}$, $23.3 \mathrm{~mL} / \mathrm{s}(10.8)$ for $18 \mathrm{~mL} / \mathrm{s}$ and $19.7 \mathrm{~mL} / \mathrm{s}(6.43)$ for $36 \mathrm{mg} /$
$\mathrm{mL}$; there were no significant differences from $0 \mathrm{mg} / \mathrm{mL}$. For bout 2, mean volume was $210.8 \mathrm{~mL}$ (261.13) for $0 \mathrm{mg} / \mathrm{mL}$, $208.4 \mathrm{~mL}(170.2)$ for $8 \mathrm{mg} / \mathrm{mL}, 124.2 \mathrm{~mL}$ (70.7) for $18 \mathrm{mg} / \mathrm{mL}$ and $84.3 \mathrm{~mL}(44.25) \mathrm{mL}$ for $36 \mathrm{mg} / \mathrm{mL}$; mean duration was $5.8 \mathrm{~s}(2.07)$ for $0 \mathrm{mg} / \mathrm{mL}, 6.1 \mathrm{~s}$ (2.21) for $8 \mathrm{mg} / \mathrm{mL}, 5.35$ (1.98) for $18 \mathrm{mg} / \mathrm{mL}$ and $4.17 \mathrm{~s}(1.55)$ for $36 \mathrm{mg} / \mathrm{mL}$; and mean flow rate was $33.0 \mathrm{~mL} / \mathrm{s}(31.5)$ for $0 \mathrm{mg} / \mathrm{mL}, 31.5 \mathrm{~mL} / \mathrm{s}(21.7)$ for $8 \mathrm{mg} / \mathrm{mL}, 22.8 \mathrm{~mL} / \mathrm{s}(10.1)$ for $18 \mathrm{~mL} / \mathrm{s}$ and $20.4 \mathrm{~mL} / \mathrm{s}(8.7)$ for $36 \mathrm{mg} / \mathrm{mL}$. For bout 2 , a significant $(\mathrm{p}<0.05)$ difference in puff duration was observed for $36 \mathrm{mg} / \mathrm{mL}$ compared to $0 \mathrm{mg} / \mathrm{mL}$ in bout $2(\mathrm{t}(15)=4.1)$.

\section{DISCUSSION}

These results demonstrate that, in experienced ECIG users, mean plasma nicotine concentration after 10 puffs from a 3.3-Volt ECIG with a 1.5 -Ohm dual-coil cartomiser is related directly to liquid nicotine concentration. At the highest concentration $(36 \mathrm{mg} / \mathrm{mL}$ ), we observed a difference (post-bout minus pre-bout) in plasma nicotine concentration of $24.1 \mathrm{ng} / \mathrm{mL}$ (18.3). This 'nicotine boost' appears greater than is typically observed in combustible cigarette smokers under similar puffing conditions (ie, $\sim 15 \mathrm{ng} / \mathrm{mL}$ ). ${ }^{14} 17$ Thus, some ECIGs appear capable of exceeding the nicotine delivery profile of a combustible tobacco cigarette. We speculate that this excessive nicotine delivery may be harmful if it leads to a greater level of nicotine dependence, which could make ECIG cessation difficult if users eventually choose to try to quit their ECIG use. Alternatively, users of higher nicotine liquid concentration may control nicotine intake by altering their puffing behaviour. Nonetheless, there is no clear rationale for a product that potentially delivers more nicotine than a tobacco cigarette, thus policymakers worldwide may want to consider limiting access to ECIG device/liquid combinations that demonstrate this nicotine delivery profile.

The puff topography results reported here were consistent with some previous reports, ${ }^{10}{ }^{11}$ but not with one other report, ${ }^{18}$ which reported lower puff volume and shorter puffs. This difference may reflect a different product used ('cigalikes') and/or sensitivity differences in topography measurement systems. ${ }^{10}$ Interestingly, there was a significant $(\mathrm{p}<0.05)$ difference in puff duration in the $36 \mathrm{mg} / \mathrm{mL}$ condition relative to the $0 \mathrm{mg} / \mathrm{mL}$ condition in bout 1 (and a non-significant trend for lower puff volume in this bout), and these results suggest that participants may have altered their puff topography in order to titrate nicotine delivery in the $36 \mathrm{mg} / \mathrm{mL}$ condition. If so, the plasma nicotine results in the $36 \mathrm{mg} / \mathrm{mL}$ condition are all the more striking, as they indicated that even when attempting to titrate nicotine delivery, users may still receive more nicotine from some ECIGs than from a combustible cigarette over a 10-puff-use bout.

This study has important limitations. As a preliminary report, the study lacked sensitivity for many comparisons and a larger sample size would allow statistical techniques that take into account the overall experiment-wise error rate. ${ }^{16}$ Also, results obtained from this study's 10-puff regimen may differ from those obtained after ad libitum puffing, during which users have the opportunity to control puff number and thereby alter the nicotine dose they receive. Additionally, because this study included no naturalistic observation, the nicotine delivery profile of users' usual liquid/device combination outside of the laboratory is uncertain. Another limitation, not unique to this study, is that assessing ECIG abstinence is problematic, as there are no rapid measures that can be used for this purpose (as expired air $\mathrm{CO}$ is used to assess abstinence from combustible tobacco). The 


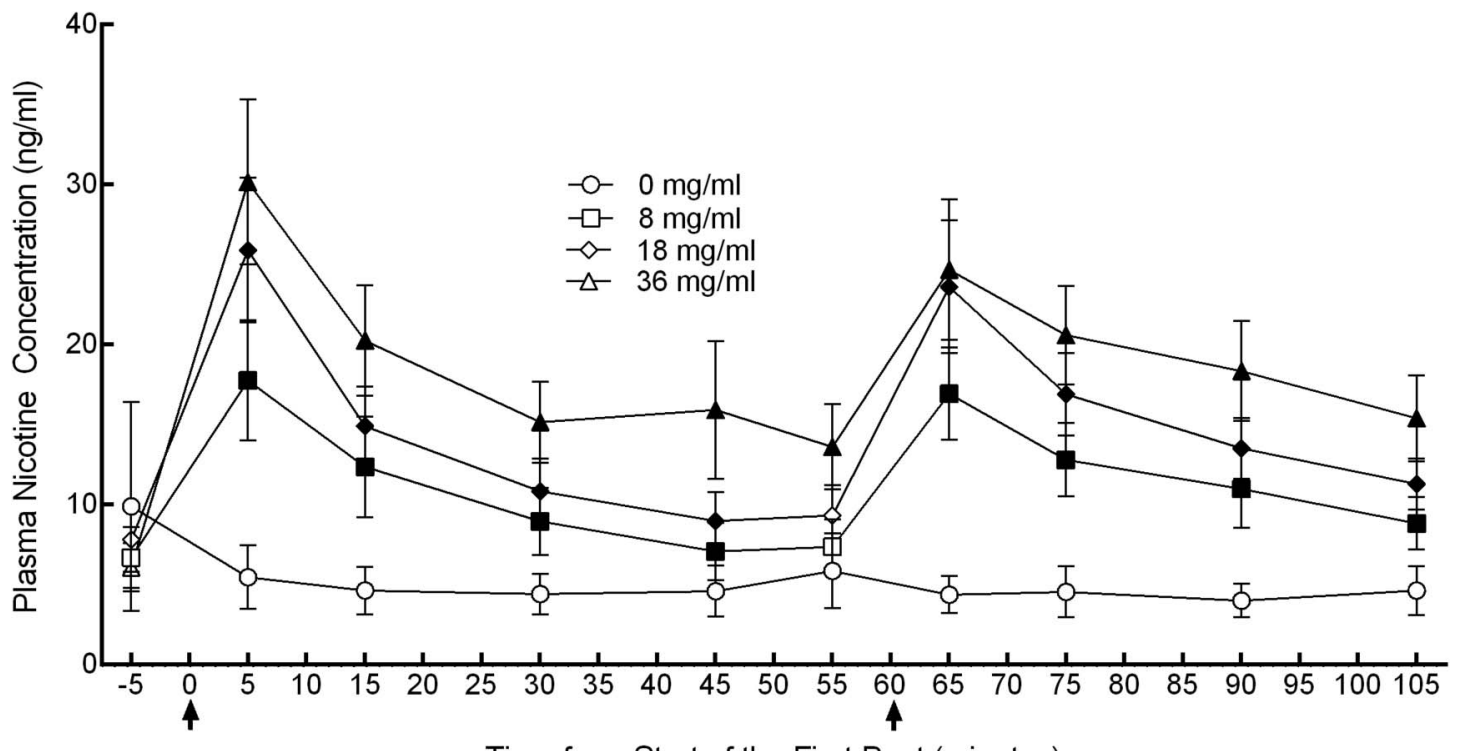

Time from Start of the First Bout (minutes)

Figure 1 Plasma nicotine concentration versus time as a function of electronic cigarette (ECIG) nicotine concentration. Mean $( \pm$ SEM) plasma nicotine values for 16 experienced ECIG users using ECIGs that varied by liquid nicotine concentration. Bouts consisting of ECIG use for 10 puffs with a $30 \mathrm{~s}$ inter-puff interval are denoted by arrows. Filled symbols indicate a significant $(p<0.05)$ difference from $0 \mathrm{mg} / \mathrm{mL} \mathrm{ECIG} \mathrm{liquid} \mathrm{at} \mathrm{that} \mathrm{time} \mathrm{point.}$

baseline plasma nicotine concentrations are higher than those reported in combustible tobacco users following $12 \mathrm{~h}$ abstinence, which may indicate that at least some participants did not fully comply with the presession abstinence requirement. Finally, the results reported here were obtained from a homogeneous sample that was primarily Caucasian and male. In future work, we hope to be able to explore the extent to which gender and ethnicity play a role in determining ECIG effects.

\section{What this paper adds}

Previous studies examining the ability of electronic cigarettes to deliver nicotine used a variety of devices and liquid nicotine concentrations, and demonstrated wide variability with some device/liquid combinations delivering no nicotine and others approximating the nicotine delivery profile of a combustible cigarette. This is the first study to hold all device and liquid characteristics constant while varying liquid nicotine concentration, and it demonstrates that user plasma nicotine concentration increases with the nicotine concentration of the liquid and, at the highest liquid nicotine concentration tested, the nicotine delivery profile of the electronic cigarette exceeded that of a tobacco cigarette tested under similar-use conditions. There is no clear rationale for an electronic cigarette that exceeds the nicotine delivery of a combustible tobacco cigarette, and policymakers may want to limit access to such liquids/devices.

Acknowledgements The authors thank CSTP staff Barbara Kilgalen, Kathleen Osei and Kendall Pettaway for their contribution to this study.

Contributors All the authors contributed to the conceptualisation and preparation of the review, and approved the final text. CPR drafted the manuscript. MMH, TRS and AAL aided in data analysis. ABB and AS revised the methods and results sections for errors. NK and TL reviewed the final manuscript. TE reviewed the updated version, edited and finalised it.

Funding This research was supported by the National Institute on Drug Abuse of the National Institutes of Health under Award Number P50DA036105 and the
Center for Tobacco Products of the US Food and Drug Administration. The content is solely the responsibility of the authors and does not necessarily represent the views of the $\mathrm{NIH}$ or the FDA.

Competing interests None declared.

Patient consent Obtained.

Ethics approval The Virginia Commonwealth Institutional Review Board.

Provenance and peer review Not commissioned; externally peer reviewed.

\section{REFERENCES}

1 Bunnell R, Agaku I, Arrazola R, et al. Intentions to smoke cigarettes among never-smoking US middle and high school electronic cigarette users: National Youth Tobacco Survey, 2011-2013. Nicotine Tob Res 2015;17:228-35.

2 Li J, Newcombe R, Walton D. The prevalence, correlates and reasons for using electronic cigarettes among New Zealand adults. Addict Behav 2015;45: 245-51.

3 McMillen R, Gottlieb M, Shaefer R, et al. Trends in electronic cigarette use among U.S. adults: use is increasing in both smokers and nonsmokers. Nicotine Tob Res Published Online First: 6 Nov 2014. doi:10.1093/ntr/ntu213

4 King B, Alam S, Promoff G, et al. Awareness and ever-use of electronic cigarettes among U.S. adults, 2010-2011. Nicotine Tob Res 2013;15:1623-7.

5 Regan A, Promoff G, Dube S, et al. Electronic nicotine delivery systems: adult use and awareness of the 'e-cigarette' in the USA. Tob Control 2013; 22:19-23.

6 Grana R, Popova L, Ling P. A longitudinal analysis of electronic cigarette use and smoking cessation. JAMA Intern Med 2014;174:812-13.

7 Bullen C, McRobbie H, Thornley S, et al. Effect of an electronic nicotine delivery device (e cigarette) on desire to smoke and withdrawal, user preferences and nicotine delivery: randomised cross-over trial. Tob Control 2010;19:98-103.

8 Farsalinos K, Spyrou A, Tsimopoulou K, et al. Nicotine absorption from electronic cigarette use: comparison between first and new-generation devices. Sci Rep 2014;4:4133.

9 Vansickel A, Eissenberg T. Electronic cigarettes: effective nicotine delivery after acute administration. Nicotine Tob Res 2013;15:267-70.

10 Spindle T, Breland A, Karaoghlanian N, et al. Preliminary results of an examination of electronic cigarette user puff topography: the effect of a mouthpiece-based topography measurement device on plasma nicotine and subjective effects. Nicotine Tob Res 2015;17:142-9.

11 Hua M, Yip H, Talbot P. Mining data on usage of electronic nicotine delivery systems (ENDS) from YouTube videos. Tob Control 2013;22:103-6.

12 Farsalinos K, Romagna G, Tsiapras D, et al. Evaluation of electronic cigarette use (vaping) topography and estimation of liquid consumption: implications for research protocol standards definition and for public health authorities' regulation. Int J Environ Res Public Health 2013:10:2500-14.

13 Talih S, Balhas Z, Eissenberg T, et al. Effects of user puff topography, device voltage, and liquid nicotine concentration on electronic cigarette nicotine 
yield: measurements and model predictions. Nicotine Tob Res 2015;17: $150-7$.

14 Vansickel A, Cobb C, Weaver M, et al. A clinical laboratory model for evaluating the acute effects of electronic "cigarettes": nicotine delivery profile and cardiovascular and subjective effects. Cancer Epidemiol Biomarkers Prev 2010;19:1945-53.

15 Breland A, Kleykamp B, Eissenberg T. Clinical laboratory evaluation of potential reduced exposure products for smokers. Nicotine Tob Res 2006;8:727-38.
16 Keppel G. Design and analysis, a researcher's handbook. Englewood Cliffs, NJ: Prentice Hall, 1991.

17 Yan XS, D'Ruiz C. Effects of using electronic cigarettes on nicotine delivery and cardiovascular function in comparison with regular cigarettes. Regul Toxicol Pharmacol 2015;71:24-34.

18 Behar R, Hua M, Talbot P. Puffing topography and nicotine intake of electronic cigarette users. PLOS ONE 2015;10:e0117222. 